\title{
Locus of control and readiness to conjure and believe in mystical powers among small business operators in Entebbe, Uganda: A multilevel rasch rating scale model analysis
}

\author{
Aloyce R. Kaliba ${ }^{1 \star}$, Robert Isabalija ${ }^{1}$, Victor W. Mbarika ${ }^{1}$, Mathieu K. Kourouma ${ }^{1}$, Carlos \\ Thomas ${ }^{1}$, Moya M. Bukoma ${ }^{2}$, Wilson M. Mande ${ }^{2}$, Mohammed Ndifuna ${ }^{2}$ and Akodo Robinah ${ }^{2}$ \\ ${ }^{1}$ Southern University, A and M College, Baton Rouge, USA. \\ ${ }^{2}$ Makerere University College of Business, Kampala, Uganda.
}

Accepted 17 May, 2011

\begin{abstract}
High external locus of control and readiness to conjure and believe in mystical powers has a potential in disrupting the growing small and medium enterprises in Uganda. If small business operators abdicate their responsibilities to mystical powers, it will worsen the current low survival rate of start-up businesses. In this study, we use a multilevel Rasch Rating Scale models to estimate a latent scale for locus of control and a composite scale that combine three domains: altitude towards wealth acquisition; paranormal beliefs; and readiness to seek wealth from mystical powers. Correlation analysis was also conducted to determine the association between the two latent scales. The data was collected from a random sample of 60 business operators in Entebbe, Uganda. Results indicate that low education and religion affiliations were determining factor for high external locus of control and readiness to conjure and believe in mystical powers. Public education through religious organization is therefore important in addressing these negative issues that may affect immerging entrepreneurship in Uganda.
\end{abstract}

Key words: Business operators, locus of control, polytomous Rasch models, Uganda.

\section{INTRODUCTION}

In Uganda, as in many African countries and some Asian countries, the practices of conjuring mystical powers is based on deep rooted beliefs in witchcraft and superstition. For instance, in their studies in Bangladesh (one of the underdeveloped countries in Asia), Alam et el. (2009) and Alam (2009) find some kind of cultural and economical similarity in witchcraft and superstition believes with Uganda. Witchcraft and superstition in various anthropological, religious and mythological contexts, is the alleged use of supernatural or mystical powers to harm and protect or acquire and accumulate wealth (Asante and Mazima, 2009). In Uganda, it is widely believed that witches can use these powers to inflict

${ }^{\star}$ Corresponding author: E-mail: aloyce_kaliba@subr.edu. Tel: 2257715952. harm upon members of a community or their property. Also, they can compel the aid of spirits to grow and expand their client's businesses or wealth. Most Ugandans believes that that personal economic windfall is a sign of assistance from occult sources or supernatural or mystical powers. Often, relatively rich people are besieged by suspicions of witchcraft and having connections to mystical powers. Therefore, wealth becomes a marker of connection to mystical powers. Moreover, majority of Ugandan look at witchcraft and superstition as an extension of their religious beliefs (Geschiere, 1998).

These beliefs are not unique in Uganda. Paris (2000) studied a group of young entrepreneurs in Ghana who operated business in large commercial cities, and who visited shrines in rural areas in order to buy protection from witchcraft and conjuring the mystical powers for more wealth. These beliefs and practices are also wide spread among different tribes in Kenya (Harries, 2010) 
and common in Ghana (Akrong, 2007). Geschiere (1998) shows that the obsession with seeking wealth from mystical powers should not be viewed as some sort of traditional residue. On the contrary, modern developments coincide with a proliferation of the economies of the occult. Examples include the upsurge of spirit cults in Taiwan and China, during economic booms (Weller, 1982; Lang and Ragvald, 1998). Paranormal beliefs and readiness to seek wealth from mystical powers have implications on how business operates and make management decisions. They have a direct effect on growth and performance of the business.

This study is a follow-up on one issue that have generated immense curiosity and concern in Uganda. For the better part of 2004, there were allegations that some small business operators were consulting the mystical powers in pursuit of wealth acquisition and accumulation. The matter attracted the spotlight of both the international and local dailies and a plethora of views from people of different shades. In particular, the Worldwide Religious News paper cited the Uganda Muslim leader as having asked the government to probe the act of people seeking wealth from mystical powers.

Bukedde newspaper, a local daily, ran a series of articles in which a number of personalities admitted to have had consulted witches to conjure mystical powers on their behalf. In particular, Bazibumbira (2004) quoted the head of Traditional Healers Association in Uganda as having admonished people against seeking wealth from mystical powers because it involves human sacrifices. Mutebi (2004) interviewed a Seventh Day Adventist Pastor who had investigated the subject of people seeking wealth from mystical powers. The pastor confirmed to know individuals who seek wealth from mystical powers. Kizito (2004) reported about a Kampala businessman who had spent 20 years learning to invoke mystical powers for individual success. The common feature among individuals who claimed to engage in these activities was motivated by wealth acquisition. Those who failed attributed their failures to inability to closely follow the rules and providing human sacrifices.

We believe that this study is important especially for the Uganda's economy on four counts: 1) to seek wealth from mystical powers has a potential of disrupting the bludgeoning Small and Medium Enterprises (SMEs) sector in Uganda. Some Small Business operators would not apply themselves fully in their businesses trusting in the providence of the mystical powers; 2) given their ability to generate employment and contribution towards poverty reduction, there is great support for Uganda's SMEs as a panacea for economic growth and development; 3) the SMEs in Uganda are vulnerable given the tenuous financial bases on which many of them hinge, and low levels of education manifested among many operators; and 4) whilst Uganda has been lauded as being among the most entrepreneurial country in Africa (Acs and Szerb, 2010), the survival rate of businesses is very low. If Uganda's small business operators abdicate their responsibility to external forces the situation could be exacerbated.

To our knowledge no study has hitherto focused on the nexus of locus of control and readiness to conjure and believe in mystical powers among small business operators in Uganda and elsewhere. This is an area that requires empirical investigations given the past intense national debate on the potential negative impact of these phenomena. Results could help in designing effective intervention programs that are tailored to educate the public on negative effects of these activities especially on business survival, performance, and growth in Entebbe and other regions in Uganda.

We depart from similar studies that focus on association between locus of control and paranormal beliefs by using an extended two-level Rasch Rating Scale model to estimate latent scales for locus of control and readiness to conjure and believe in mystical power. Definitions of locus of control and paranormal beliefs are available in literature. For this study we follow the text book definition of readiness, which is defined as a disposition to respond to some phenomenon. To have readiness, therefore, implies a willingness, eagerness, and preparedness to something. In a sense it is an orientation toward seeking mystical powers for protection and wealth accumulation.

\section{LITERATURE REVIEW}

\section{Important definitions and past studies}

Rotter (1966) defines locus of control as an individual's perception about the underlying main causes of events in life. Zimbardo (1985) adds that a locus of control orientation is a belief about whether the outcomes of our actions are contingent on what we do (internal control orientation) or on events outside our personal control (external control orientation). Under internal locus of control an individual believes that his/her behavior is guided by his/her personal decisions and efforts. Internal locus of control is associated with self-agency, personal control, and self-determination. External locus of control occurs if an individual believes that his/her behavior is guided by fate, luck, or other external circumstances such as mystical powers. The Rotter's locus of control scale therefore measures the extent of a person's internal or external reinforcement beliefs.

As postulated by Rotter (1966), the locus of control is a fundamental personality trait referring to individual differences in a generalized belief in internal versus external control of reinforcements. A business operator with high internal locus of control will attribute changes related to success and failure to personal action and business environment. Such a person considers oneself to be an active agent in charge of one's business environment and destiny. A business operator with a high 
external locus of control sees oneself as a passive agent and believes that the events in life are caused by uncontrollable forces outside of oneself; such as fate, chance, God, spiritual powers etc (Howard, 1996; Wang et al., 1999; Boone et al., 2000).

Therefore, in business, locus of control refers to the extent to which business operators believe that they can control events that affect their business profitability and growth. Operators with a high internal locus of control believe that business performance is influenced by their own business plans and actions (Ray, 1984). Business operators with high external locus of control believe that fate, or chance primarily determine business outcome including performance and growth. Individuals with high internal locus of control are more active in seeking information and knowledge concerning their business. The propensity to engage in activities to influence business growth is stronger for operators who have a high internal locus of control than for those who have a high external locus of control.

The literature supports a casual relationship between locus of control and readiness to conjure and believe in mystical powers (Williams and Irwin, 1991; Dag, 1999; Peltzer, 2003). Beliefs in mystical powers are those beliefs which, if genuine, would violate basic limiting principles of science (Tam and Shiah, 2004; Wiseman and Watt, 2004). In this study, it is assumed that attitude towards wealth acquisition and paranormal beliefs are conjugates for seeking wealth from mystical powers. The three domains reinforce each other to form a continuum latent trait. Tobacyk (1995) presents 26 items and techniques that can be used to measure Paranormal Belief Scale using a seven-point Likert rating scale. The scale is composed of seven subscales: traditional religious belief, Psi, witchcraft, superstition, spiritualism, extraordinary life forms, and precognition. It should be noted that some items used to construct the subscale may be regional specific. For example, the existence of abominable snowman of Tibet and the Loch Ness monster of Scotland are not familiar in the African continent mythology, especially in Uganda. These items are not universal can be modified to reflect beliefs that are common in a study area.

Considerable research has been carried out on locus of control (Adams, 2000; Sohn and Leckenby, 2001; Thielker et al., 2001; Shewchuk et al., 1990). Stanke (2004) used analysis of variance to identify specific characteristics that are associated with locus of control. The conclusion was that levels of religiosity do not have a significant relationship with levels of superstitious or paranormal beliefs that influence locus of control. Positive correlation existed among external locus of control with superstitious beliefs. In order to understand the relationship between locus of control and paranormal beliefs, Groth-Marnat and Pegden (1998) conducted a study that included 81 undergraduate students. They used a structured questionnaire and respondent responses were used to construct the paranornomal belief, Rotter's locus of control, and sensation seeking scales. Results indicated that a greater external locus of control was associated with greater overall number of paranormal beliefs. Greater external locus of control was especially associated with the Paranormal Belief subscales of spirituality and precognition. Contrary to expectations, belief in superstition was associated with a greater internal locus of control. Whereas overall sensation seeking was not related to overall paranornomal belief, the paranornomal belief subscales of greater belief in psi phenomena and superstition were found to be associated with higher levels of sensation seeking.

In their study, Tobacyk et al. (1987) studied the relationships between paranormal beliefs and locus of control. The paranormal beliefs scale and Paulhus's Spheres of Control Scale were administered to 349 introductory college students. The results indicated a significant correlation between greater personal efficacy control and less belief in superstition and witchcraft, and greater interpersonal control and less belief in superstition. Burke et al. (2006) used Pearson correlation analysis to determine the relationship between measures of belief in personal control and superstitious behavior among NCAA Division I Intercollegiate Student-Athletes. They concluded that statistically significant positive correlation existed between internal locus of control and optimism. A statistically significant negative correlation existed between high internal locus of control and lower pessimism. Dag (1999) used the Turkish version of Tobacyk's revised Paranormal Belief Scale and the Rotter's Locus of Control Scale to study the relationships between paranormal beliefs and locus of control and psychopathology in a sample of Turkish college students. The conclusion was that the revised paranormal belief subscales predicted locus of control better and the psychopathology subscales. While evidence from these studies indicates that locus of control has an important influence on individual belief and decisions, few studies use quantitative techniques to measure the influence of individual demographic variables on these phenomena. This is important in designing customer tailored intervention programs.

\section{Quantitative latent variable measurement}

Locus of control, attitude towards wealth acquisition, paranormal beliefs and readiness to seek wealth from mystical powers are all latent variables. Latent variables are characteristics that cannot be directly measured or directly observable. Latent variables can be measured indirectly through their effects on observable indicators using specific questions or statements commonly known as items (Bradley et al., 2006). Response to each item may be analyzed separately or all items may be summed to create a summative score or a summative latent scale. 
Generally, it is not advisable to make inferences based upon the analysis of a single-item response that is used in measuring a scaled latent variable (Johnson and Albert, 1999).

In addition, individual items often suffer from random measurement error especially when several items measure the same latent trait. It is therefore statistically appropriate to create a scale out of these items. A scale will be more parsimonious and reliable than analyzing each item individually (Bradley et al., 2006). When the structure of items is based on a Likert scale, responses are normally treated as ordinal data. This is because one cannot assume that respondents perceive the difference between adjacent levels as equidistant (Fox, 2005). That is, if the data are ordinal, we can say that one score is higher than another, however, we cannot say how much higher.

When responses to several items are summed to measure a latent variable and all statement in a survey instrument use the same Likert scale, the responses are treated as interval data. The interval data tells the distance between two points and the differences between each response are equal in distance (Zheng and RabeHesketh, 2009). Interval estimates of a latent continuum scale that is based on the Likert scale responses can be obtained by applying the Polytomous Rasch Models. The polytomous Rasch model is a generalization of the dichotomous Rasch model (Rasch, 1960).

The model permits testing of the hypothesis that the statements in the Likert scale reflect increasing levels of the latent variable as intended (Bryk and Raudenbush, 1992; Tesio, 2003; Rabe-Hesketh and Skrondal, 2008). For ordered Likert scale responses, the polytomous Rasch model is also known as a Rating Scale model (RSM). The model assumes identical threshold distances across items (Andrich, 1978).

To operationalize the Rating Scale Model, let $X$ be a data matrix made up by the responses of $v=1 \ldots \mathrm{N}$ person who responds to $\mathrm{k}=1, \ldots, \mathrm{K}$ polytomous items with the same number $h=1, . ., M$ response categories per item (that is, Likert scale with $\mathrm{M}$ response categories). The subjects are in the low and items (statements) in the column. The polytomous rating scale model (RSM) as suggested by Andrich (1978) is:

$$
P\left(X_{v k}=h \mid \theta_{v}\right)=\frac{\exp \left(h\left(\theta_{v}+\beta_{k}\right)+\gamma_{h}\right.}{\sum_{l=1}^{M} \exp \left(l\left(\theta_{v}+\beta_{k}\right)+\gamma_{l}\right.} .
$$

$$
\text { Level } 1 \text { (individua l): }
$$

$$
\text { Level } 2 \text { (Group): }
$$

In Equation 3, $\mathrm{z}$ is a matrix of individual level covariates with a total numbers of $Q$ variables. The intercept $\left(\alpha_{0 i}\right)$ is
Equation 1 express the probability of giving any one of the possible response categories by respondent $v$ on items $i$. The coefficient, $\beta_{k}$, is the vector of item parameters, $\theta_{v}$ is the vector of subject parameters and $\gamma_{h}$ is the vector of category parameters (sometimes known as step parameters), which are the same for all items. The parameters, $\theta_{v}$ equal the subject's interval value of the latent scale to be measured. For example it may represent individual level of locus of control or readiness to conjure and believe in mystical powers for wealth acquisition and accumulation.

As the values of $\theta_{v}$ increase, the probability of selecting response $h$ in a monotonic manner increases. The $\beta_{k}$ parameters measure the marginal or location effect for item $k$, which depend on both the response option and the particular item. The sum in the denominator ensures that for respondent $v$ the sum of probabilities $\left(P\left(X_{v k}=h / \theta_{v}\right)\right.$ over all response options to item $k$ equals one. To conform to the Rasch Model methodology, the items effects are constant or fixed across persons. For strictly ordered and increasing thresholds, the following constraints are usually imposed as shown in Equation (2):

$$
\sum_{h=1}^{m} \gamma_{h}=0, \quad \text { and } \quad \gamma_{1}<\gamma_{2}<\cdots<\gamma_{h}
$$

When constraints in Equation (2) are imposed, all consecutive differences defining the item category response functions will be negative and the sum of the item category response function will add to one. For parameter identification purposes $V_{h}$ is usually set to zero (Chajewski and Lewis, 2009). Notice that in Equation 1 the latent variable parameter $\left(\theta_{v}\right)$ varies across respondents. Therefore, personal level variables can be introduced to capture the source of variability and nesting within groups. Multilevel modelling is therefore needed to capture variability in individual responses and by group. Following Fox (2005), defines a general multilevel model with covariates such that respondents $(v=1, \ldots, N)$ are nested within group $(i=1, \ldots, I)$. A two level rating scale model that estimate a latent variable that depends on individual respondent characteristics and that vary by groups is:

$$
\begin{aligned}
& P\left(X_{v k}=h \mid \theta_{v i}\right)=\frac{\exp \left(h\left(\theta_{v i}+\beta_{k}\right)+\gamma_{h}\right.}{\sum_{l=1}^{m} \exp \left(l\left(\theta_{v i}+\beta_{k}\right)+\gamma_{l}\right.}, \\
& \theta_{v i}=\alpha_{0 i}+\sum_{q=1}^{Q} \alpha_{q i} z_{q i}+\varepsilon_{v i}, \\
& \alpha_{0 i}=\eta_{00}+\mu_{i} .
\end{aligned}
$$

the average value of the latent variable for each group after controlling for the covariates. The parameters $\alpha_{q i}$ 
represents the marginal effects of individual level covariates on the latent variable. The error term $\left(\varepsilon_{v i}\right)$ which is assumed to be normally distributed with zero mean and a constant variance $\left(\alpha_{0 i} \sim \mathrm{N}\left(0, T_{10}\right)\right)$ represents individual level random variation of the latent trait after controlling for demographic characteristics. In level-2 model, the intercept for the level 1 model $\left(\alpha_{0 i}\right)$ is decomposed into fixed effects $\left(\eta_{00}\right)$ and random effect that vary across groups $\left(\mu_{i}\right)$. It is also assumed that $\mu_{i}$ $\sim \mathrm{N}\left(0, T_{20}\right)$. The fixed effect $\left(\eta_{00}\right)$ is the sample mean of the estimated latent variable. The random effect represents variations in the estimated latent variable across group. If a small variance is observed, it would imply that the latent variable is similar across groups. If a large variance is observed, it means that the latent trait differs by groups (Zheng and Rabe-Hesketh, 2009).

\section{Validity and reliability test of the survey instrument}

As mentioned before, latent traits are indirectly measured using several responses on items that are collected using a survey instrument. When constructing scales, naturally we want to know how good the scale is. How reliable is the scale? What items belong in the scale? Therefore, before estimating the latent trait, responses have to be tested for validity and reliability. Validity refers to the extent to which a survey instrument measures what it intended to measure. There are a variety of ways to evaluate validity. However, for a single survey the focus is on construct validity. Construct validity refers to whether a survey instrument measures or correlates with the theorized construct that it purports to measure (Golafshani, 2003). Construct validity defines how well an experiment measures up to its claims and determine to whether the operational definition of items actually reflects the true theoretical meaning of a concept. Highly correlated items that fit the expected pattern contribute evidence of construct validity.

Usually, construct validity is a judgment based on the accumulation of correlations from numerous studies using the instrument being evaluated (Healy and Perry, 2000; Campbell, 1959). For a single survey that use an equidistant Likert scale, construct validation it is therefore equivalent to empirically testing the second expression in Equation (2). Does moving from a lower to an upper response category increases the magnitude of the latent trait variable? Instead of imposing the second expression in Equation (2), it can be tested empirically.

By definition, reliability refers to the accuracy and precision or consistency of a survey instrument (Thorndike et al., 1991). All survey instruments that use different items to construct a scale constitute some degree of inconsistency. The inconsistency in a set of items arises from variation across individuals plus all other sources of variability within and across the items. Variability is also made up of true values of the items and error or noise. For a survey instrument, reliability measures the ratio of the variability of the true values of the items to the sum of variability of the true values of the items and associated errors. Reliability of a survey instrument is increased by reducing error variance and by increasing the variance of the true value (Brennan, 2001).

Any survey instrument is reliable if there are greater interindividual variations in the sample or population. While there are several measures of reliability, for single survey the focus is on internal consistency reliability.

This measures the extent to which all of the items in the model measure the same construct. Do all the items tend to move together (same direction) or do some items move to different direction. Internal consistency is measured by Cronbach's coefficient alpha, which summarizes the average correlation between all possible pairs of items (Cronbach, 1971). In other words, Cronbach's coefficient alpha (a) measures how well a survey instrument measures a single and one dimension latent construct. It quantifies the internal consistency of the instrument or the average correlation of items within the instrument. It is a first step towards measuring construct validity and reliability of the survey instrument (Cronbach, 2004). The acceptable value of Cronbach's coefficient alpha ( $\alpha$ ) depends on the objective of the study. However, the value between 0.6 and 0.8 is commonly accepted (Blalock, 1970; Cortina, 1993; Zinbarg et al., 2006).

In summary, reliability refers to the degree to which a psychometric instrument is consistent and stable in measuring what it is intended to measure. The instrument is reliable if it is consistent within itself and across time. Validity refers to the degree to which the instrument actually measures what it claims to measure. Validity determines the extent to which inferences, conclusions, and decisions made on the basis of psychometric instrument are appropriate and meaningful. Therefore, validity is a prerequisite to testing for reliability. If a test is not valid, then reliability is also doubtful.

\section{METHODOLOGY}

\section{Source of data and data description}

A sample of 60 small business operators in the Entebbe Business District, Uganda was randomly selected to participate in the current study. The sample included 30 service providers and 30 general traders. The sample businesses were selected from a list obtained from the Entebbe Business District business register office. The business registrar office divides small business into two groups: service provider and general traders. They are also classified as small and medium enterprises if they employ less than 20 and 100 people, respectively. This study concentrated on small businesses. Based on the list, these businesses constituted more than $80 \%$ of all small and medium enterprises in the Entebbe Business District.

Before administering the survey, content validity of the survey instrument was substantiated by a focus group. The focus group carefully reviewed the survey instrument and assisted in providing guidance in constructing the instrument statements. In addition, they were required to determine whether the instrument statement looks valid in terms of measuring the intended latent traits (that is, locus of control and readiness to conjure and believe in mystical powers). They also rated each statement/item to determine how 
essential a particular statement is; in measuring the particular latent trait. Statements of the survey instrument were added, dropped and modified based on the focus group suggestions.

The final survey instrument with 24 items was divided into the following subsections: altitude towards wealth acquisition (4 items), locus of control ( 7 items), paranormal beliefs ( 4 items), and readiness to seek wealth from under water spirits ( 8 items), and demographic section. The items were on a five Likert scales (1=Strongly Disagree; $2=$ Disagree; $3=$ neither agree nor disagree; $4=$ agree; and $5=$ strongly agree). The demographic section collected data on gender, age, education level, religion, and marital status of the respondent. The survey instrument was administered to business owner or manager using a face-to-face interview.

Summary statistics of the responses from all 60 respondents are presented in Table 1. In the sample, majority of respondents were single and young males (less than 20 year), with secondary level education or lower. There was a slightly high representation for individuals from Catholic and Anglican denominations. In Table 1 and for items, percent frequency includes "neither agree nor disagree", "agree", and "strongly agree" categorical responses. For example, most of the responses in the attitude towards wealth acquisition were in the neither agree or disagree and agree category.

Except for one item in the locus of control domain (other people tends to dominate my decision making process), most of responses to other items were in the last three response categories. For paranormal beliefs domain, most responses from one item (spirits exist but are not all that powerful to grant anything) was in the last three categorical responses. Responses on other items were in the strongly disagree and disagree response categories. Similarly, two items in the readiness to seek wealth from under water spirits domains ("If the spirits are able to grant wealthy, I will use them" and "I believe that spirits can make miracles in one's life and business") were in the strongly disagree and disagree response categories. Most of responses on other items were in the upper response categories. In general, if the percent frequency is less than $50 \%$, the most of the responses were in the strongly disagree and disagree response categories and vice versa.

\section{Data analyses}

Variable clustering approach was used to test the validity and reliability of the survey responses using alpha command in the statistical package Stata. The command computes inter-item correlations or covariance for all specified items. This is in addition to computing Cronbach's coefficient alpha statistic for the scale formed by the items. This procedure also iteratively divides groups of items into subscales until a stopping criterion is reached. This a more direct way of creating a survey instrument that measure same construct and direction or grouping questions that measure the same construct. In Stata, the alpha command can be used to assess how well the items form a single scale that measure the same construct (Stata, 2009).

Equation (3) was used to estimate the latent trait that measures locus of control scale and a composite scale constructed from items representing altitude towards wealth acquisition, paranormal beliefs and readiness to seek wealth from under water spirits. The three domains created a latent trait measuring readiness to conjure and believe in mystical powers. Due to relatively small sample size and few items that measures some of the latent traits the "Strongly Disagree" and Disagree" responses were combined to form a "disagree" response category. Therefore, the Rasch Rating Scale Model has four response categories: disagree $=1$; neither agree or disagree=2; agree=3; and strongly disagree=4).

For demographic variables, due to low frequency of "Widowed" response, the marital status variable was collapsed to a dichotomous variable (that is, single or widowed=1; and zero otherwise). Also, in order to conform to the standard Rasch model, four dichotomous variables representing education levels (that is, University, College, Secondary, and Other) and religion affiliation (Anglican, Catholic, Muslim, and Evangelical) were constructed. For education variable, individuals with primary education were combined with those who did not attend school to form a single dummy variable. Therefore, the level-1 covariates included a dummy variable for gender (male $=1$; zero otherwise), an ordered variable for age, three dummy variables for education level, three dummy variables for religion affiliation, and a dummy variable for marital status. The other dummy for education and Evangelical dummy variable were not include in the model to avoid perfect collinearality.

As specified in Equation (3), two latent traits (locus of control scale and readiness to conjure and believe in mystical powers) were estimated using gllamm program also in Stata. The program gllamm runs in the statistical package Stata and estimates GLLAMMs (Generalized Linear Latent and Mixed Models) by maximum likelihood. An advantage of using gllamm directly is that the latent variables (common factors or random effects) can be assumed to be discrete or to have a multivariate normal distribution (Zheng and Rabe-Hesketh, 2009).

In addition, simple linear correlation analyses (Pearson $r$ ) were conducted to determine the relationship between the estimated two latent traits. Pearson correlation assumes that the variables are measured on at least interval and it determines the extent to which values of the two or more variables are proportional to each other. The advantage is that the value of correlation (that is, correlation coefficient) does not depend on the specific measurement units used; which is important for latent traits constructed using different items (Stata, 2009)

\section{RESULTS AND DISCUSSION}

\section{Validity and reliability tests}

Results of validity and reliability tests for all items are presented in Table 2. The estimated Cronbach's coefficient indicated that items included to measures altitude towards wealth acquisitions and readiness to seek wealth from mystical powers strongly measure these latent construct $(\alpha>0.6)$. However, the items used to measure locus of control and paranormal beliefs were weak in measuring these latent construct $(\alpha<0.6)$. When data have a multidimensional structure Cronbach's alpha will usually be low. For locus of control and paranormal beliefs either the questions asked were either few or not clear enough to create the intended measure or latent scale.

In Table 2 and for all items, the second Eigen values for altitude towards wealth acquisition, locus of control, and readiness to seek wealth from under water spirits are greater than 1. This means that all items in the domain are not represented by a single construct or different items are either moving in the same direction but measuring different constructs or are measuring same construct but in different directions. Therefore these domains met the criterion for splitting. Altitude towards wealth acquisition subscale was split into two clusters. The first cluster constituted all items in the domain except the "Anything that is likely to bring in wealth is welcome." Therefore, the three remaining items formed the first cluster. Likewise, the locus of control domain was divided 
Table 1. Summary Statistics for all variables used in the study ${ }^{1}$

\begin{tabular}{|c|c|c|}
\hline Subscale & Category/ltems & Frequency (\%) \\
\hline \multicolumn{3}{|c|}{ Demographic characteristic } \\
\hline \multirow{2}{*}{ Business types } & Service & 50.00 \\
\hline & General traders & 50.00 \\
\hline \multirow{2}{*}{ Gender } & Male & 63.33 \\
\hline & Female & 36.67 \\
\hline \multirow{3}{*}{ Age } & Less than 20 years of age & 58.33 \\
\hline & Between $20-30$ years of age & 31.67 \\
\hline & Above 30 years of age & 10.00 \\
\hline \multirow{5}{*}{ Education } & University & 18.33 \\
\hline & Some College & 25.00 \\
\hline & Secondary & 45.00 \\
\hline & Primary & 10.00 \\
\hline & Illiterate & 1.67 \\
\hline \multirow{4}{*}{ Religion } & Anglican & 28.33 \\
\hline & Catholic & 31.67 \\
\hline & Moslem & 20.00 \\
\hline & Evangelicals & 20.00 \\
\hline \multirow{3}{*}{ Marital status } & Single & 51.67 \\
\hline & Married & 46.67 \\
\hline & Widowed & 1.67 \\
\hline \multirow{4}{*}{$\begin{array}{l}\text { Attitude towards Wealth } \\
\text { Acquisition (WEA) }\end{array}$} & Life is meaningless without wealth (LIFE) & 73.33 \\
\hline & My reason for working is primarily to acquire wealth (WORKING) & 73.33 \\
\hline & I will do anything to become wealthy (ANYTHING) & 91.67 \\
\hline & Anything that is likely to bring in wealth is welcome (BRING) & 58.33 \\
\hline \multirow{7}{*}{ Locus of Control (LOCI) } & Whatever happens in my life and business is my own doing (WATEVER) & 61.67 \\
\hline & I believe that I control my own destiny (CONTROL) & 68.33 \\
\hline & I always rely on others to make business decisions (RELAY) & 41.67 \\
\hline & Other people tend to dominate my decision making process (OTHER) & 48.33 \\
\hline & Factors other than me determine the direction of my business (FACTOR) & 53.33 \\
\hline & My success in business is achieved through personal effort (SUCCESS) & 75.00 \\
\hline & Misfortunes I face in business are consequences of my mistakes (MISFORT) & 96.67 \\
\hline
\end{tabular}


Table 1. Contd.

\begin{tabular}{|c|c|c|}
\hline \multirow{4}{*}{ Paranormal Beliefs (PB) } & I believe spirits do exist (SPIRITS) & 41.67 \\
\hline & Spirits are a mere figment of people's imaginations (MERE) & 28.33 \\
\hline & Spirits exist but are not all that powerful to grant anything (SPIEXIS) & 73.33 \\
\hline & Spirits have always influenced people's actions (SPI) & 41.67 \\
\hline \multirow{8}{*}{$\begin{array}{l}\text { Readiness to seek wealth } \\
\text { from under water spirits } \\
\text { (RSWS) }\end{array}$} & If the spirits are able to grant wealthy, I will use them (GRANTS) & 33.33 \\
\hline & I believe spirits are able to influence business success (BELSPI) & 66.67 \\
\hline & Some wealthy business people acquired their success from mystical powers(RICH) & 78.33 \\
\hline & Mystical powers are more accessible than God (ACCESS) & 95.05 \\
\hline & I have no moral inhibition to seeking business success from mystical powers(INHIBIT) & 56.67 \\
\hline & Without the support of the spiritual forces one cannot succeed in business (WITHOUT) & 93.33 \\
\hline & I believe that spirits can make miracles in one's life and business (SPIMAKE) & 48.33 \\
\hline & I believe spirits can take care of my enemies including business competitors (SPICAN) & 61.67 \\
\hline
\end{tabular}

${ }^{1}$ For item parameters the percent frequency is include "Neither Agree or Disagree", "Agree" and "Strongly Agree" responses

Table 2. Test for Items reliability and validity.

\begin{tabular}{|c|c|c|c|}
\hline Subscale and New Clusters & Cronbach's coefficient alpha $(\alpha)$ & Items $^{1}$ & Second Eigen value \\
\hline Altitude towards Wealth Acquisition (AWA) & 0.66 & All items & 1.02 \\
\hline AWA Cluster 1 & 0.69 & life, working, anything & 0.90 \\
\hline Locus of Control (LOCI) & 0.35 & All items & 1.59 \\
\hline LOCI Cluster 1 & 0.41 & whatever, control, factor, success & 0.99 \\
\hline LOCI Cluster 2 & 0.48 & other, relay, misfort & 0.80 \\
\hline Paranormal Beliefs (PB) & -0.24 & All items & 0.88 \\
\hline Readiness to Seek Wealth from Under Water Spirit (RSWS) & 0.64 & All items & 1.35 \\
\hline RSWS Cluster 1 & 0.78 & grant, rich, access, without, spmake, spican & 0.87 \\
\hline RSWS Cluster 2 & -0.69 & BELSPI, INHIBIT & 0.76 \\
\hline
\end{tabular}

${ }^{1}$ See table 1 for definition of variables.

into two clusters. The first cluster contained four items and the second cluster contained three items as shown in Table 2. Readiness to seek wealth from under water spirit was also subdivided into two clusters containing, respectively, six and two items. In all cases, variable clustering improved validity and reliability outcome.

Results in Table 2 also indicate that the two clusters of the locus of control domain were both measuring a similar latent construct $(\alpha>0)$.
However, the items in the readiness to see wealth from under water spirits were measuring same construct but in different directions. The Cronbach coefficient alpha for cluster one is in an acceptable range and positive and Cronbach coefficient 
Table 3. Estimated item parameters for the locus of control rating scale model.

\begin{tabular}{|c|c|c|c|}
\hline Item & Coefficient & Std. Err. & $P>|Z|$ \\
\hline \multicolumn{4}{|l|}{ Variables include in the Level-1 Model: Item Variables } \\
\hline Whatever happens in my life and business is my own doing. & 0.112 & 0.153 & 0.081 \\
\hline I believe that I control my own destiny & 0.029 & 0.133 & 0.095 \\
\hline I always rely on others to make business decisions & -0.328 & 0.198 & 0.098 \\
\hline Other people tend to dominate my decision making process. & -0.503 & 0.252 & 0.027 \\
\hline Factors other than me determine the direction of my business & 0.413 & 0.145 & 0.036 \\
\hline My success in business is achieved through personal mistakes & 0.137 & 0.154 & 0.077 \\
\hline Misfortunes I face in business are consequences of my mistakes & -1.074 & 0.490 & 0.028 \\
\hline \multicolumn{4}{|c|}{ Variables included in Level-2 Model: Influence of demographic characteristics on Locus of control } \\
\hline Gender & -0.011 & 0.239 & 0.000 \\
\hline Age & -0.137 & 0.104 & 0.455 \\
\hline Marital Status & 0.101 & 0.315 & 0.005 \\
\hline University education & -0.693 & 1.942 & 0.011 \\
\hline College education & -0.255 & 0.209 & 0.422 \\
\hline Secondary education & -0.244 & 0.212 & 0.433 \\
\hline Anglican & -0.044 & 0.177 & 0.001 \\
\hline Catholic & -0.108 & 0.202 & 0.076 \\
\hline Muslim & 0.082 & 0.204 & 0.022 \\
\hline Variance: Level-1model & 0.191 & 0.128 & 0.126 \\
\hline Variance: level-2 model & 0.659 & 0.001 & 0.000 \\
\hline Step two $\left(\gamma_{3}-\gamma_{2}=0\right)$ & 1.545 & 0.294 & 0.000 \\
\hline Step three $\left(\gamma_{4}-\gamma_{3}=0\right)$ & 2.698 & 0.241 & 0.004 \\
\hline Chi- square test $\left(\gamma_{2} \geq \gamma_{3} \geq \gamma_{4}\right)$ & 83.060 & & 0.000 \\
\hline
\end{tabular}

alpha for cluster 2 is in an acceptable range and negative. In particular and by reviewing the questions asked, items in cluster one measured the general overview of an individual on locus of control and items in cluster two were more specific about personal evaluation (evaluation of personal character) about locus of control. Similarly, items in cluster one on readiness to seek wealth from under water spirits asked questions regarding general beliefs and the two items in cluster two asked individual to evaluate themselves about these beliefs. Therefore, while all items in these domains measured the same construct, the level and direction of measurement were different. These results give an insight now how the results of the rating scale model should be interpreted.

\section{Results of the rasch rating scale model}

Results of estimated item parameters for the locus of control model and readiness to conjure and believe in mystical powers are presented in Tables 3 and 4, respectively. Also in Tables 3 and 4, the likelihood ratio tests the hypothesis that variables all included in the model are not statistically significant. In both models the hypothesis is rejected at more than $1 \%$ level of significance. This means that at least some of the variables included in the model explain observed individual variations in locus of control and readiness to conjure and believe in mystical powers. The Chi-Square test is a lower tail test for the second expression in Equation (2). In the both cases, the null hypothesis is $\left(\gamma_{2} \geq \gamma_{3} \geq \gamma_{4}\right)$, which is rejected at more than $1 \%$ level of significance. Because we have four categorical responses, there are three step parameters. Step one is moving from disagree to neither agree nor disagree responses. Step two is moving from "neither agree nor disagree" to "agree" responses and step three is moving from "agree" to "strongly agree" responses. Step one is a reference step. In the second and third steps, we use a two tail test t-test to test the null hypotheses that $\gamma_{3}-\gamma_{2}=0$ and $\gamma_{4}-\gamma_{3}=0$, respectively. The alternative hypotheses are $\gamma_{3}-\gamma_{2} \neq 0$ and $\gamma_{4}-\gamma_{3} \neq 0$, respectively. Both null hypotheses are rejected at more $1 \%$ level of significance. The combined results of the Chi-square and t-test suggest that; overall, the items included in the locus control and readiness to conjure and believe in mystical powers have strong and consistent construct validity.

The first part of Table 3 shows the estimated coefficients or item parameters for all variables included in the rating scale model. All item variables are statistically 
significant at more than $10 \%$ level of significance. This is acceptable for one time cross sectional survey. The magnitude of the estimated coefficient determines the position of the item on thelocus of control scale. Low score means that the item was easy; most respondents scored the item as agree or strongly agree. High score means that the item was difficulty; most respondents scored the item as disagree, which is a low score. The three statements: misfortunes I face in business are consequences of my mistakes; other people tend to dominate my decision making process; and I always rely on others to make business decisions are on the left side of the locus of control scale (high internal locus of control). These results correspond to the results in Tables 1 and 2. In Table 1, majority of respondents (about $100 \%$ ) agreed with the first statement. Relatively few respondents (about $42 \%$ and $48 \%$ ) agreed to the second and third statements, respectively. In Table 2, the three items/statements are in the same cluster. However, note that the Cronbach's coefficient alpha is positive and not negative. This is because the structure of the questions is such that locus of control scale is increasing (from negative infinity to positive infinity) or from internal locus of control sub-scale to external locus of control sub-scale. In most cases, disagree responses were associated with internal locus of control and strongly agree responses were associated with external locus of control.

The remaining items/statements in the first part of Table 3 are on the left side of the locus of control scale (external locus of control). These statements (in order of importance) include: factors other than me determine the direction of my business, my success in business is achieved through personal mistakes, whatever happens in my life and business is my own doing and I believe that I control my own destiny. Except for the item/statement "factors other than me determine the direction of my business", though statistically significant, the estimated coefficients for other remaining items/statements are close to the middle of the locus of control scale. From Table 2, about $58 \%$ of the responded agreed with the first statement and between 60 and $75 \%$ of the respondents agreed with the remaining statements.

The second part of Table 3 shows the influence of individual characteristics on locus of control. The variable that were statistically significant at more than $10 \%$ level of significance were gender, marital status, university education, and all dummy variables for religion affiliation. Male business owners are more likely to have higher internal locus of control when compared to female, which is obvious in the male dominated world. Single and the widowed business owners are likely to have high external locus of control when compared to married business owners. In particular, most respondents who agreed with the statement "I always relay on others to make business decisions" where single and widowed business owners. Lack of reliable family and social support tends to create dependence and therefore vulnerable to external locus of control.

While increase in age increased internal locus of control, the age variable was not statistically significant (Table 3). This can be attributed to the fact that majority of business owner where in the same age group. One average, a business operator with a university education has a higher internal locus of control when compared to a business owner with primary education or less. College education and secondary education dummy variables are not statistically significant but have expected signs, negative. This means that business operator with college education or secondary education has a slightly higher internal locus of control when compared to a business owner with primary education or less. Also, the estimated coefficients for the education dummy variables are in a descending order. From secondary education to university education; implying that internal locus of control increases with education level. On average, Catholics and Anglicans are more likely to have a high internal locus of control when compared to evangelicals. However, evangelicals are more likely to have high locus of control when compared to Muslim. This may be related to religious teaching and individual spirituality; a topic beyond this study.

Correspondingly, the first part of Table 4 presents the results of rating scale model on readiness to conjure and believe in mystical powers. All items/statements were statistically significant at more than $10 \%$ level of significance. The sign and the magnitude of the coefficient determine the location of the item on the readiness to conjure and believe in mystical power scale. High score mean the item/statement is difficulty or few respondents agreed with the statement (low score) and vice versa. Four items/statements with high value of estimated coefficients (in a descending order) include: spirits are a mere figment of people's imaginations; if the spirits are able to grant wealthy, I will use them; I believe spirits do exist; and spirits have always influenced people's actions. Similarly, five items/statements with low values of estimated coefficients included: without the support of the spiritual forces one cannot succeed in business; mystical powers are more accessible than God; I will do anything to become wealthy; my reason for working is primarily to acquire wealth; and life is meaningless without wealth.

For the first group and the second group of items the estimated coefficients (difficult parameters) ranged between 1.53 and 1.11 and -0.41 and 0.05 , respectively. For the remaining items/statements the estimated coefficients ranged between 0.24 and 0.90 . These results suggest that majority of respondents disagreed with the first group of four items/statements $\left(\beta_{k}>1\right)$ and majority of respondent strongly agreed with the second group of items/statements $\left(\beta_{\mathrm{k}}<0.05\right)$. For remaining items/ statements and for majority of respondents, the responses were "neither agree nor disagree" or "disagree". It can be noted that while majority of respondents were skeptical about spirit existence, most of them were ready to do 
Table 4. Estimated item parameters for the readiness to conjure and believe in mystical powers.

\begin{tabular}{|c|c|c|c|}
\hline Item & Coefficient & Std. Error & $P>|Z|$ \\
\hline \multicolumn{4}{|l|}{ Variables of Level-1 Model: Item variables } \\
\hline Life is meaningless without wealth & 0.045 & 0.023 & 0.049 \\
\hline My reason for working is primarily to acquire wealth & 0.050 & 0.026 & 0.058 \\
\hline I will do anything to become wealthy & -0.222 & 0.103 & 0.032 \\
\hline Anything that is likely to bring in wealth is welcome & 0.521 & 0.254 & 0.042 \\
\hline I believe spirits do exist & 1.172 & 0.265 & 0.000 \\
\hline Spirits are a mere figment of people's imaginations & 1.526 & 0.283 & 0.000 \\
\hline Spirits exist but are not all that powerful to grant anything & 0.579 & 0.254 & 0.024 \\
\hline Spirits have always influenced people's actions & 1.107 & 0.263 & 0.000 \\
\hline If the spirits are able to grant wealthy, I will use them & 1.318 & 0.271 & 0.000 \\
\hline I believe spirits are able to influence business success & 0.238 & 0.126 & 0.060 \\
\hline Some wealthy business people acquired their success from mystical powers & 0.464 & 0.254 & 0.070 \\
\hline Mystical powers are more accessible than God & -0.351 & 0.127 & 0.007 \\
\hline I have no moral inhibition to seeking business success from mystical powers & 0.550 & 0.254 & 0.032 \\
\hline Without the support of the spiritual forces one cannot succeed in business & -0.410 & 0.127 & 0.002 \\
\hline I believe that spirits can make miracles in one's life and business & 0.896 & 0.257 & 0.001 \\
\hline I believe spirits can take care of my enemies including business competitors & 0.594 & 0.254 & 0.021 \\
\hline \multicolumn{4}{|c|}{$\begin{array}{l}\text { Variable of Level-2 Model: Influence of demographic characteristics on readiness to conjure and believe in } \\
\text { mystical powers }\end{array}$} \\
\hline Gender & 0.125 & 0.094 & 0.186 \\
\hline Age & 0.079 & 0.070 & 0.260 \\
\hline Marital Status & -0.155 & 0.103 & 0.136 \\
\hline University education & -0.550 & 0.256 & 0.032 \\
\hline College education & -0.363 & 0.149 & 0.016 \\
\hline Secondary education & -0.173 & 0.052 & 0.001 \\
\hline Anglican & -0.014 & 0.007 & 0.040 \\
\hline Catholic & -0.044 & 0.012 & 0.000 \\
\hline Muslims & 0.125 & 0.042 & 0.006 \\
\hline Variance level- 1 model & 0.032 & 0.029 & 0.270 \\
\hline Variance level-2 model & 3.842 & 1.384 & 0.006 \\
\hline Step two $\left(\gamma_{3}-\gamma_{2}=0\right)$ & 0.591 & 0.4175 & 0.001 \\
\hline Step three $\left(\gamma_{4}-\gamma_{3}=0\right)$ & 0.904 & 0.250 & 0.000 \\
\hline Chi- square test $\left(\gamma_{2} \geq \gamma_{3} \geq \gamma_{4}\right)$ & 13.400 & & 0.000 \\
\hline Likelihood ratio test & -50.279 & & 0.000 \\
\hline
\end{tabular}

anything to acquire wealth including conjuring. Also, the statement "without the support of the spiritual forces one cannot succeed in business" may be misreading. Respondents may have confused spiritual forces with religious beliefs and superstitions and thus giving conflicting responses.

The lower part of Table 4 shows the estimated coefficients on the influence of demographic characteristics of the respondents on readiness to conjure and believe in mystical powers. All education and religion dummy variables were statistically significant at more than $5 \%$ level of significance. Readiness to conjure and believe in mystical powers decreased with increase in education level. Anglican and Catholics were less likely to conjure and believe in mystical powers than evangelicals. However, Muslims were more likely to conjure and believe in mystical powers when compared to Evangelicals. Therefore, education and religion were the most important variables that influenced the readiness to conjure and believe in mystical powers.

In addition, both Tables 3 and 4 show results of estimated level-1 and level-2 variances. In Table 3 the level1 variance was 0.19 and was not statistically significant. After controlling for demographic characteristics there 
Table 5. Comparison of estimated latent traits by type of business.

\begin{tabular}{|c|c|c|c|c|}
\hline \multirow{2}{*}{ Estimated latent traite } & \multirow{2}{*}{ Summary statistic } & \multicolumn{2}{|c|}{ Type of business } & \multirow{2}{*}{ Sample } \\
\hline & & Service & Trade & \\
\hline \multirow{3}{*}{ Internal locus of control } & Mean & -0.084 & -0.078 & -0.081 \\
\hline & Standard deviation & 0.112 & 0.126 & 0.118 \\
\hline & Frequency & 21 & 17 & 38 \\
\hline \multirow{3}{*}{ External locus of control } & Mean & 0.202 & 0.175 & 0.189 \\
\hline & Standard deviation & 0.088 & 0.061 & 0.075 \\
\hline & Frequency & 9 & 13 & 22 \\
\hline \multirow{3}{*}{ Sample } & Mean & 0.002 & -0.002 & -0.001 \\
\hline & Standard deviation & 0.169 & 0.161 & 0.163 \\
\hline & Frequency & 30 & 30 & 60 \\
\hline \multirow{3}{*}{ Not likely to conjure and believe in mystical powers } & Mean & -0.185 & -0.254 & -0.217 \\
\hline & Standard deviation & 0.141 & 0.303 & 0.230 \\
\hline & Frequency & 22 & 10 & 32 \\
\hline \multirow{3}{*}{ Likely to conjure and believe in mystical powers } & Mean & 0.407 & 0.309 & 0.351 \\
\hline & Standard deviation & 0.182 & 0.197 & 0.193 \\
\hline & Frequency & 8 & 20 & 28 \\
\hline \multirow{3}{*}{ Sample } & Mean & 0.012 & 0.010 & 0.001 \\
\hline & Standard deviation & 0.032 & 0.038 & 0.035 \\
\hline & Frequency & 30 & 30 & 60 \\
\hline
\end{tabular}

was little variability on locus of control across respondents. The Level -2 variance was 0.659 and was statistically significant at more than $1 \%$ level of significance. This means that the estimated locus of control varied by types of business. In Table 4, the level-1 variance was 0.032 and was also not statistically significant. Likewise, level-2 variance was statistically significant at more than $5 \%$ level of significance indicating variation in readiness to conjure and believe in mystical powers by type of business.

The summary statistics of estimated level of locus of control and readiness to conjure and believe in mystical powers are presented in Table 5. These latent traits were standardized and ranged from -3 to 3 for practical purposes. As shown in Table 5, majority of business operators (38 out of 60), have internal locus of control. The service sector has more business operators with internal locus of control when compared to the trade sector. Likewise, external locus of control was more common in the trade sector. This can be attributed to type of customers served. The service sector tends to have a customer base that is stable and predictable. The customer base in the trading sector tends to be unstable therefore creating more business competition in the sector. These results translate into the second part of Table 5. Majority of business operators in the service sector are not likely to conjure and believe in mystical powers (22 out of 30 ) and majority business operators in the trading sector (20 out of 30 ) are likely to conjure and believe in mystical powers. Trade competition may be behind these phenomena.

Correlation analysis was also conducted to determine the association between the estimated locus of control index and readiness to conjure and believe in mystical powers scores. The estimated Pearson correlation coefficient was 0.62 for the entire sample. Test for independence was rejected at $5 \%$ level of significance. Also, correlation analyses were conducted by business types. The Pearson correlation coefficient was 0.81 for the trade sector and 0.56 for the service sector. Again, tests for independence for both sectors were rejected at $5 \%$ level of significance. These results suggest that there was a strong positive relationship between external locus of control and readiness to conjure and believe in mystical powers. Business operators with high external locus of control were more likely to be ready to conjure and believe in mystical powers. Due to inherent business completion, this relationship was strong in the trade sector than in the service sector. Apart from culture that shape beliefs, stiff business competition can be associated with external locus of control and readiness to conjure and believe in mystical powers among small 
business operators in Uganda.

\section{CONCLUSION AND POLICY IMPLICATIONS}

In this study, we used a two-level linear Rasch Rating Scale models to estimate latent traits related to locus of control and readiness to conjure and believe in mystical powers. The second level models were used to determine the influence of demographic characteristics on locus of control and readiness to conjure and believe in mystical powers. Readiness to conjure and believe in mystical powers was constructed from several items that measured attitude towards wealth acquisitions, paranormal beliefs, and readiness to seek wealth from mystical powers. Correlation analysis was also conducted to determine the relationship between locus of control and readiness to conjure and believe in mystical powers.

Data was collected from a random sample of business operators in Entebbe Business District, Uganda. Uganda is known as an entrepreneurship country. High external locus of control and readiness to conjure and believe in mystical powers has potential of upsetting the achievement made. A business operator with high external locus of control will attribute failure or success to mystical powers and a focus will be on conjuring and not business improvement as the way it was suggested by Alam et al. (2010). High external locus of control means that business operators are not realistic about available opportunities they can use to develop or expand their businesses. They will depend on chances or certain things to happen to them through mystical powers.

Results from this study indicate that education and religion variables have a strong influenced on both locus of control and readiness to conjure and believe in mystical powers. Alam et al 2010 and Alam, 2009 also strongly stressed these variables in the context of Bangladesh. Majority of respondents have average scores in terms of locus of control and were lukewarm on the influence of mystical powers on business outcomes. This is an indication that there is unrealistic optimism about business outcomes among business operators in Uganda. This can be attributed to culture. The way a person is brought up, the situations they encounter in life, and the views that they are exposed to are key factors in the development of such attitudes and beliefs. Another cultural way that attitudes and beliefs are formed is through one's experience with religion. As indicated in

this study and elsewhere there are surmount evidence indicating that religion, and the beliefs associated with it, affect one's decision making process not only in life but in business operation.

Post-secondary business and entrepreneurship education and participation by religious institutions are fundamental in improving locus of control and changing people's attitude on mystical powers and wealth accumulation. Similar explanations in the context of Bangladesh was made by Alam et al. (2010) and Alam and Khlifah (2009) The Ugandan government should collaborate with other non-government organization such as Uganda Chambers of Commerce to organize seminars and short term training on business management and entrepreneurship. Religious institutions need to synergize their messages on the importance of internal locus of control on business decision making, focusing on personal responsibility and accountability as pillars of success in business. In addition, mass media has a significant social influence that can shape and legitimize social behavior and personal beliefs. The mass media is an important objective means of communication for social change. Mass media programs aimed at small business operators in Uganda is highly recommended. The mass media will provide effective and efficient mechanisms for imparting positive attitude towards business management and dispensing the myth of using mystical power to accumulate wealth. The focus should be on understanding the essence of business competitions and associated technical solution through hard work and accountability of business operators.

\section{ACKNOWLEDGEMENT}

This research was based upon work supported by the National Science Foundation grant \# 0644305. We also thank anonymous reviewers for their valuable comments. However, any opinions, findings, and conclusions or recommendations expressed in this paper are those of the author(s) and do not necessarily reflect the views of the NSF or AJBM.

\section{REFERENCES}

Acs JZ, Szerb L (2010). The global entrepreneurship and development index. Paper presented the summer conference on opening up innovation, strategy, organization and technology at Imperial College , London Business School, June 16 - 18, Available at: http://www2.druid.dk/conferences/viewpaper. php? $\mathrm{id}=502261 \& \mathrm{cf}=43$

Adams S (2000). The impact of religiosity and locus of control on academic achievement in college students. Available at: http://www.webster.edu/ hulsizer/research/Adams.pdf

Akrong A (2007). A phenomenology of witchcraft in Ghana. In: Gerrie Ter Haar, (Ed). Imagining evil: witchcraft beliefs and accusations in contemporary Africa. Trenton, NJ: Africa World Press Inc.

Andrich D (1978). A rating scale formulation for ordered response categories. Psychometrika, 43(4): 561-573.

Alam GM (2009). Can governance and regulatory control ensure private higher education as business or public goods in Bangladesh? Afr. J. Bus. Manage., 3 (12): 890-906.

Alam GM, Hoque KE, Rout GK, Priyadarshani N (2010). Who gains from EFA -State Business of Education or Private Higher Education Business in Developing Nation: A study to understand the policy impact in Bangladesh? Afr. J. Bus. Manage., 4(5): 770-789.

Alam GM, Hoque KE, Oloruntegbe KO (2010). Quest for a better operation system in Education: Privatization, Teacher Educationalization or Voucherilization: glimpsing from consumer and product perspectives. Afr. J. Bus. Manage., 4(6): 1202-1214.

Alam GM, Hoque KE, Ismail L, Mishra PK (2010). Do Developing Countries need education laws to manage its system or are ethics and market-driven approach sufficient? Afr. J. Bus. Manage., 
4(15): 3406-3416.

Alam GM, Hoque KE, Khalifa MTB, Siraj SB, Ghani MFBA (2009). The role of agriculture education and training on agriculture economics and national development Alam GM, Khalifa MTB (2009). The impact of introducing a business marketing approach to education: a study on private HE in Bangladesh. Afr. J. Bus. Manage., 3(9): 463-474.

Bazibumbira $F$ (2004). For the mystical powers to grant you wealth you first promise to sacrifice human blood. Bukedde 10th September. 11: 218.

Blalock HM (1970). Estimating measurement error using multiple indicators and several points in time. Am. Sociol. Rev., 35(1): 101-111.

Bradley K, Sampson S, K Royal K (2006). Applying the Rasch rating scale model to gain insight into student's conceptualization of quality mathematics instruction. Math. Educ. Res. J., 18(2): 11-26.

Brennan R (2001). An essay on the history and future of reliability from the perspective of replications. J. Educ. Measure., 38(4): 295-317.

Burke KL, Czech DR, Knight JL, Scott LA, Joyner AB, Benton SG, Roughton HK (2006). An exploratory investigation of superstition, personal control, optimism and pessimism in NCAA division I intercollegiate student athletes. Available at: www.athleticinsight.com/Vol8lss2/Superstition.htm. J. Sport Psychol., Vol. 4.

Boone C, De Brabander B, Hellemans J (2000). CEO locus of control and small firm performance. Organ. Stud., 21(3): 641-646.

Bryk AS, Raudenbush SW (1992). Hierarchical linear models: applications and data analysis methods. Newbury Park: CA Sage.

Campbell DT (1959). Convergent and discriminant validation by the multitrait- multimethod matrix. Psychol. Bull., pp. 81-105.

Chajewski M, Lewis C (2009). Optimizing item exposure control and test termination algorithm pairings for polytomous computerized adaptive tests with restricted item banks. Paper presented at the Graduate Management Admission Council Conference on Computerized Adaptive Testing. June 1-3, 2009, Minneapolis, MN.

Cortina JM (1993). What is coefficient alpha? An examination of theory and applications. J. Appl. Psychol. 78(1): 98-104.

Cronbach LJ (1971). Test validation. In Thorndike RL (Ed). Educational Measurement $\left(2^{\text {nd }} E d\right.$.). American Council on Education Washington, D.C.

Cronbach LJ (2004). My current thoughts on coefficient Alpha and successor procedures. Educ. Psychol. Measure., 64: 391-418.

Dag I (1999). The relationships among paranormal beliefs, locus of control and psychopathology in a Turkish college sample. Pers. Individ. Differ., 26(4): 723-737.

Fox JP (2005). Multilevel IRT using dichotomous and polytomous response data. Br. J. Math. Stat. Psychol., 58(1): 145-172.

Geschiere P (1998). Globalization and the power of indeterminate meaning: witchcraft and spirit cults in Africa and East Asia. Dev. Change, 29(4): 811-837.

Golafshani N (2003). Understanding Reliability and validity in qualitative Research. Qual. Rep., 8(4): 597-607.

Groth-Marnat G, Pegden J (1998). Personality correlates of paranormal belief: Locus of control and sensation seeking. Soc. Behav. Personality, 26(3): 291-196.

Harries J (2010). Witchcraft, culture, and theology in African development. African Nebula, Available at: http://nobleworld.biz/images/Harries_Witchcraft.pdf. 2: 2

Healy MP (2000). Comprehensive criteria to judge validity and reliability of qualitative research within the realism paradigm. Qual. Mark. Res., $3(3): 118-126$.

Howard DE (1996). The relationship of internal locus of control and female role models in female college students. Doctoral dissertation. University of Austin, Texas.

lam GM (2009) The role of science and technology education at network age population for sustainable development of Bangladesh through human resource advancement. Sci. Res. Essays, 4(11): 1260-1270.

Johnson V, Albert J (1999). Ordinal data modeling. New York: SpringerVerlag.
Kizito S (2004). A Businessman who sought wealth form mystical powers testifies. Bukedde, 7th September, 2004. 11: 215.

Lang G, Ragvald L (1998). Spirit-writing and the development of Chinese cults. Sociol. Rel., 59(4):309-328

Mutebi R (2004). Seeking wealth from mystical powers is a fact - said a pastor. Bukedde. 8th September, 2010. 11:216.

Paris J (2000). From the body to the wallet: conceptualizing Akan witchcraft athome and abroad. J. R. Anthropol. Instit., 6(3): 487-500.

Peltzer KA (2003). Magical thinking and paranormal beliefs among secondary and university students in South Africa. Per. Individ. Differ., 35(6): 1419-1426.

Rabe-Hesketh S, Skrondal A (2008). Multilevel and longitudinal modeling using Stata. Stata Press Publication Corp LP: College Station, TX.

Ray JJ (1984). Locus of control as a moderator of the relationship between level of aspiration and achievement motivation. J. Soc. Psychol., 124(2): 131-133.

Rasch G (1960). Probabilistic models for some intelligence and attainment tests. Copenhagen, Danish Institute for Educational Research, expanded edition (1980). The University of Chicago Press: Chicago.

Rotter JB (1966). Generalized expectations of internal locus of control in relation to achievement motivation variable. Psychol. Monogr., 80: 609

Shewchuk RM, Foelker GA, Niederehe G (1990). Measuring locus of control in elderly persons. Int. J. Aging Hum. Dev., 30(3): 213-224.

Stata (2009). Stata User's Guide Release 11: Statistics, graphics and data management. Stata Press Publication Corp LP: College Station, TX.

Sohn D, Leckenby JD (2001). Locus of control and interactive advertising. In: Proceedings of the American Academy of Advertising. 265-271.

Stanke A (2004). Religiosity, locus of control and superstitious belief. UW-L J. Undergrad. Res., Vol. VII.

Tam W, Shiah Y (2004). Paranormal belief, religiosity and cognitive complexity. Available at: http://www.parapsych.org/papers/45.pdf

Thielker V, Kwok M, Senisais M (2001). The relationship between positive reinforcement and locus of control. Available at: www.mtholyoke.edu/courses/lablouin/psych200/project_fall01/locus_ control.htm

Thorndike RM, Cunningham GK, Thorndike RL, Hagen EP (1991). Measurement and evaluation in psychology and education, fifth edition. Macmillan Publishing: New York.

Tesio $L$ (2003). Measuring behaviors and perceptions: Rasch analysis as a Tool for rehabilitation research. J. Rehabilit. Med., 35(3): 105-15.

Tobacyk JJ (1995). What is the correct dimensionality of paranormal beliefs? A reply to Lawrence's critique of paranormal belief scale. J. Parapsychol., 5:3.

Tobacyk J, Nagot E, Miller M (1987). Paranormal beliefs and locus of control: A multidimensional examination. J. Personality Assess., 52(2): 241-246.

Wang L, Kick EL, Fraser J, Burns TJ (1999). Status attainment in America: The roles of locus of control and self-esteem in educational and occupational outcomes. Sociol. Spectrum, 19(3): 281-29.

Weller RP (1982). Sectarian religion and political action in China. Modero China, 8:463-483

Williams LM, Irwin HJ (1991). A study of paranormal belief, magical ideation as an index of schizotypy and cognitive style. Pers. Individ. Differ., 12(12): 1339-1348.

Wiseman R, Watt C (2004). Measuring superstitious beliefs: why lucky charms matter. Available http://www.richardwiseman.com/resources/PAID-charm.pdf

Zinbarg R, Yovel I, Revelle W, McDonald R (2006). Estimating generalizability to a universe of indicators that all have an attribute in common: a comparison of estimators. Appl. Psychol. Measure., 30(2): 121-144.

Zheng X, Rabe-Hesketh S (2009). Estimating Parameters of Dichotomous and Ordinal Item Response Models with GLLAMM. Stat J., 7(3): 313-333.

Zimbardo PG (1985). Psychology and life. Scott Foreman and Company: Glenview, IL. 